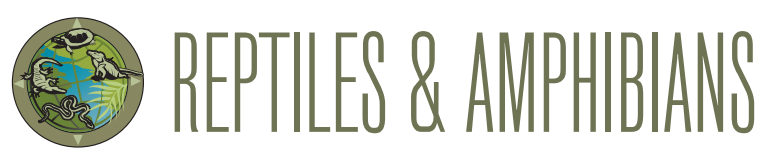

\title{
An Albino Butler's Gartersnake (Thamnophis butleri) from Milwaukee County, Wisconsin
}

\author{
Billie C. Harrison ${ }^{1}$ and Cindy Steinle ${ }^{2}$
}

${ }^{1}$ Milwaukee Public Museum, 800 West Wells Street, Milwaukee, Wisconsin 53233, USA (bharrison@mpm.edu [corresponding author]) ${ }^{2}$ Small Scale Reptile Rescue, West Allis, Wisconsin 53219, USA (cindyisteinle@gmail.com)

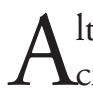
though albinism has been widely reported in many species of gartersnakes (Thamnophis spp.) (Bechtel 1995), documented examples of albinism in Butler's Gartersnake (Thamnophis butleri) are rare. One was collected in 1938 in Milwaukee County and the specimen was deposited in the Milwaukee Public Museum (MPM 2600; Dyrkacz 1981; Fig. 1). Additional records among hobbyists and in zoos are unpublished (C. Koch, Field Herp Forum, 2 September 2011, http://www.fieldherpforum.com/forum/viewtopic. php?f=2\&t=8001; J. Jundt, pers. comm., 2 July 2019).

We discovered a young (yearling?) male albino Butler's Gartersnake (SVL 333 mm, weight 10 g; Fig. 2) on 7 June 2019 in a parking lot adjacent to a 66-acre natural area in Milwaukee County, Wisconsin, USA. The exact locality is

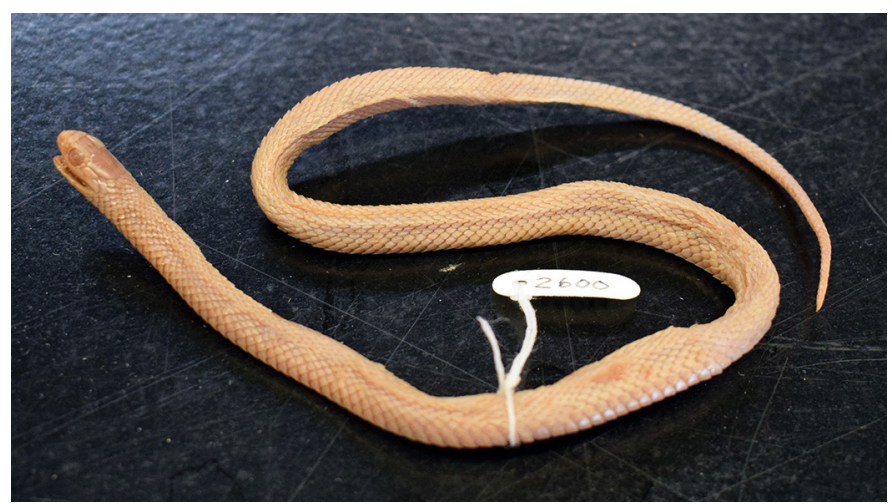

Fig. 1. An albino Butler's Gartersnake (Thamnophis butleri; MPM 2600) collected in Milwaukee County, Wisconsin, in 1938. Photograph by Billie C. Harrison.

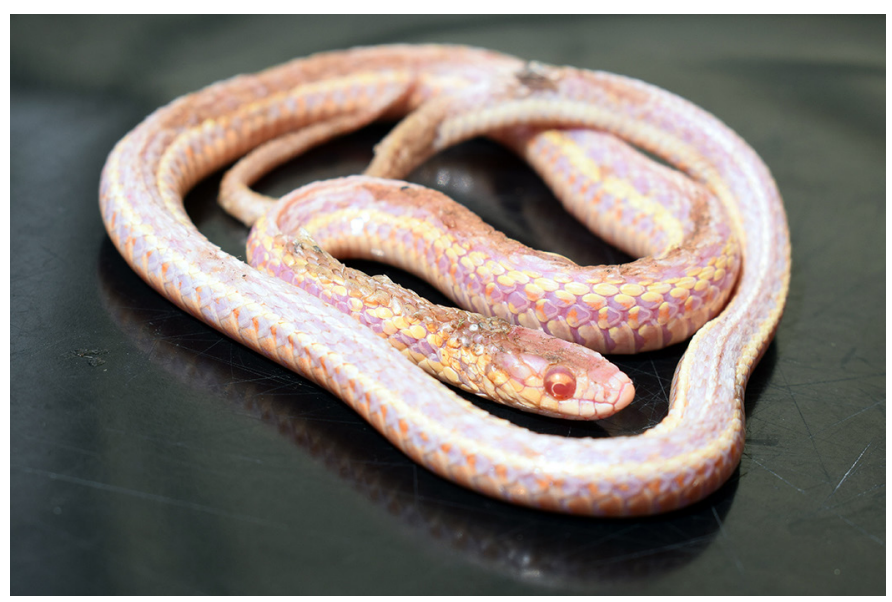

Fig. 2. An albino Butler's Gartersnake (Thamnophis butleri; MPM RA34015) collected in Milwaukee County, Wisconsin, in 2019. Photograph by Billie C. Harrison.

generalized due to collection/conservation concerns. The natural area consists of grassland and wooded wetland. Because albino animals frequently have additional physiological abnormalities, this snake was deemed unsuitable for release. The snake died while in captivity and has been deposited in the herpetology collection of the Milwaukee Public Museum (MPM RA34015).

\section{Literature Cited}

Bechtel, H.B. 1995. Reptile and Amphibian Variants: Colors, Patterns, and Scales. Krieger Publishing Co., Malabar, Florida, USA.

Dyrkacz, S. 1981. Recent instances of albinism in North American amphibians and reptiles. SSAR Herpetological Circulars 11: 1-32. 